\title{
JANELA PERIFÉRICA: A EXPERIÊNCIA DO WEBDOCUMENTÁRIO DAS CRIANÇAS DA COMUNIDADE MORADIAS ZIMBROS, REALIZADO A PARTIR DA EDUCOMUNICAÇÃ̃ ${ }^{1}$
}

\author{
Felipe Harmata Marinho \\ Priscila Pacheco ${ }^{3}$
}

\section{Resumo}

Este trabalho discute a experiência de um webdocumentário realizado a partir da educomunicação, com crianças que moram na comunidade Moradias Zimbros, localizada na periferia de Curitiba. São discutidos a infância, modelos de escolarização, representações sociais da favela e de seus moradores, além das possibilidades de trabalhar educomunicação e webdocumentário como ferramentas sociais na busca identitária.

Palavras-chave: Educomunicação, webdocumentário, criança, periferia.

\section{Abstract}

This paper discusses the experience of making a webdocumentary, along with children living in community called Moradias Zimbro, located on the suburbs of Curitiba, based on educommunication methodologies. It discusses childhood, schooling models, social representations of the "favela", as well as the possibilities of working with educommunication and webdocumentary as social tools in identity search.

Keywords: Educommunication, webdocumentary, child, suburbs.

\section{Introdução}

Este artigo apresenta a experiência do projeto Janela Periférica, um webdocumentário, com viés educomunicativo, no qual as crianças são participantes ativas nas fases de produção. O trabalho foi realizado na comunidade Moradias Zimbros, localizada no bairro Cidade Industrial de Curitiba (CIC). Mais que espectadoras, as crianças participaram como entrevistadas e produtoras de conteúdo, despertando o encontro entre criança e comunicação e desenvolvendo assim sua capacidade crítica e criadora. O resultado da experiência encontrase no site www.janelaperiferica.com.br.

\footnotetext{
1 O projeto Janela Periférica foi contemplado pelo programa InFormação, uma iniciativa da ANDI Comunicação e Direitos, com o patrocínio da Petrobras, no âmbito do projeto Jornalista Amigo da Criança, e o apoio do Fórum Nacional de Professores de Jornalismo - FNPJ.

${ }^{2}$ Mestre em Ciências Sociais Aplicadas pela Universidade Estadual de Ponta Grossa (UEPG), pós-graduado em Comunicação e Semiótica pela PUC-PR, jornalista pela Universidade Positivo, onde é professor.

${ }^{3}$ Jornalista formada pela Universidade Positivo e técnica em Produção Audiovisual para Rádio, TV e Cinema.
} 
O trabalho tem como objetivo mostrar um olhar diferente sobre a periferia, que num determinado segmento da comunicação é explorada por um viés negativo, influenciando na visão da criança sobre o seu espaço. A ideia surge de uma lacuna existente nos veículos de comunicação, em que os produtos audiovisuais são pensados para crianças e não por crianças.

Pensando nisso, a iniciativa em questão visa estimular a educomunicação como uma ferramenta que transmite valores éticos, incentivando o empreendedorismo, ampliando os possíveis horizontes educacionais e profissionais e criando uma rede de inclusão social entre os moradores da região onde o projeto foi aplicado, no caso, as Moradias Zimbros - uma das 83 comunidades localizada dentro do bairro Cidade Industrial de Curitiba, na região periférica da cidade. Essa rede, a partir da educomunicação, pode se tornar um alicerce para a transformação social e proteção das crianças envolvidas nessa iniciativa. Como afirma Schaun (2002, p. 15) sobre a educomunicação:

\begin{abstract}
A questão da Educomunicação busca ressignificar os movimentos comunicativos inspirados na linguagem do mercado da produção de bens culturais, mas que vão se resolver no âmbito da educação como uma das formas de reprodução de organização de poder da comunidade como um lugar de cidadania, aquele índice do qual emergem novas esteticidades e eticidades (modo de perceber e estar no mundo).
\end{abstract}

Baseado nessas considerações, buscou-se trabalhar com questões de inclusão, sociabilidade, senso crítico e formação do olhar com crianças de 8 a 12 anos da comunidade. Por isso, nos próximos itens o artigo discute infância, os conceito de periferia e favela até chegar na educomunicação e webdocumentário como ferramentas de transformação social e busca identitária. Por fim, é explicado o processo empírico do projeto Janela Periférica.

\title{
A infância do senso comum versus as diferentes infâncias
}

Analisar a infância hoje em dia aparenta ser uma realidade muito distante de quem analisava a mesma infância dos séculos anteriores. Mas segundo Demartini (2011, p. 12), em meio às muitas diferenças do choque de gerações, um elemento se mantém semelhante mesmo que com alguns aspectos de mudanças sociais - na infância brasileira. Trata-se das diferentes infâncias existentes em nosso país. Isto é:

Para a problematização das vivências infantis, levando-se em conta que as crianças são constituintes da realidade social, fazem parte de grupos sociais, sendo impossível pensar em uma criança "genérica", quando pensamos infância no Brasil, nos dias atuais ou em tempos pretéritos.

Ou seja, não é possível conceituar o que é a infância sem antes considerar onde a mesma está inserida, seu contexto sociocultural, histórico, familiar, econômico, entre outros 
elementos que influenciam a estrutura de vida neste período em cada ser humano. Para Demartini (2011), ao tratar do assunto infância, e consequentemente a criança, é necessário considerar que uma "grande parcela das crianças carrega em suas experiências de vida as vivências em diferentes espaços, isto é, em diferentes realidades socioeconômicas e culturais" (p. 12).

Lajolo (1997) também analisa esse 'engessamento' como a “construção de uma imagem da infância como vida sem conflitos” (p. 229), ou seja, a infância num imaginário popular como algo que sempre é remetido a uma vida feliz e serena, para a autora:

esta representação edênica da infância parece ter calado tão fundo no imaginário brasileiro [...] que se transformou em clichê, conjunto empoeirado de metáforas, que ocorre à boca de quem quer que se prepare para falar da infância.

Essa relação entre diferentes infâncias ainda se mostra presente, pois para Patrícia Dias Prado (2011) se referir à infância sem analisar as condições onde a mesma está inserida na sociedade, representa o reflexo de uma "sociedade hierarquizada e hierarquizadora das relações sociais, dividida de forma desigual, de modo que classifica os atores sociais, adultos e crianças, bem como as relações entre elas" (p. 110).

Moacyr Scliar (1995) diz que a construção da representação social da criança com elementos de senso comum sobre uma vida perfeita e idílica não pode ser garantida para todas como se existisse um único "país da infância". Para o autor, a infância não pode ser vivida por igual por todas as crianças, pois ela acontece no contexto onde cada criança vive. "Nem todas as crianças, contudo, podem viver no país da infância. Existem aquelas que, nascidas e criadas nos cinturões de miséria que hoje rodeiam as grandes cidades, descobrem muito cedo que seu chão é o asfalto hostil” (p. 4).

Com isso é necessário analisar outros espaços que também servem como cenário para a construção de representações sociais, boas ou más. Este trabalho deter-se-á a partir de agora em outro espaço representativo neste processo, a periferia.

\section{Cidades: da periferia à favela}

De um modo geral, periferia representa geograficamente toda área urbana que está ao redor dos grandes centros urbanos. Mas em um contexto contemporâneo e brasileiro, essa palavra detém outras conotações, pois nos espaços urbanos a periferia comumente passa a designar o que no Brasil é intitulado como favela (BURGOS, 2009). Dentro desta relação, 
encontram-se diversas interpretações sobre o que esses espaços representam para a sociedade. Licia do Prado Valladares (2005) define que "as favelas passam então a ser percebidas como a 'outra metade da cidade', aparecendo, antes de tudo, como o território da violência e da pobreza, da ilegalidade frente a cidade 'legal'” (p. 20).

Segundo Pedro Strozemberg (2009), o processo de formação das favelas é marcado por um espírito de tensão em grande parte das cidades brasileiras. Isso porque "a favela, ou as favelas por sua múltipla representação, são historicamente identificadas como a expressão de antítese da ordem pública, e percebidas pelo conjunto da sociedade como espaço transgressor" (p. 67). Essa identificação, para o autor, pode ocorrer tanto por ser considerado por muitos um espaço que extrapola limites geográficos, quanto um espaço que extrapola limites morais.

Com isso, a dita "cidade favela" e a "cidade oficial" estabelecem sua convivência pautada pela autonomia e invisibilidade. Pedro Strozemberg (2009) afirma que por essa invisibilidade e por estarem "empenhadas em sobreviver, as favelas se impõem no território e criam regras de solidariedade opondo-se a imagem externa criada como locus da exclusão" (p. $68)$.

Segundo Burgos (2009), essa visão engessada e de terceiros sobre o que a favela representa acabou "convertendo-se em instrumento de luta e de afirmação identitária" (p. 52). Ou seja, este conjunto de construções cristalizadas sobre a favela pode servir como estímulo a reapropriação da favela por parte de seus moradores. Mas para isso é preciso que eles passem a enxergar sua realidade social a partir da alteridade, ou seja, a significância de que assim como o indivíduo consegue enxergar outros, ele também precisa se enxergar como outro (KRAMER, 2000), não negando que existem diferenças, mas sim que elas constroem o ser único. Isso se dá em um processo de busca identitária, que uma vez que seja estimulada, influencia também na busca pela valorização da cultura e da história das comunidades locais, com o intuito de estimular a preservação e reforço das identidades culturais do bairro periférico e consequentemente de seus moradores. Este trabalho busca influenciar nesse processo de alteridade junto a comunidade Moradias Zimbros, utilizando para isso duas ferramentas comunicacionais: a educomunicação e o webdocumentário.

\section{Pela tela, pela janela: a educomunicação como ferramenta social da busca identitária}

A educomunicação age como uma intersecção entre os campos da comunicação e da educação. Ou seja, o educomunicador trabalha um novo campo de intervenção social denominado de educomunicação, educar para a comunicação. O conceito busca a construção de um ambiente comunicativo aberto, criativo, colaborativo, educativo e que quebre a 
hierarquia na construção do saber (SCHAUN, 2002). Enxergando a educomunicação desta maneira, é possível configurá-la como um novo campo de intervenção social, propício a encontros reflexivos aos mais variados temas, é o que diz Ismar de Oliveira Soares (2004), ao afirmar que

reconhecer a comunicação como o mais importante dos eixos transversais dos processos educativos foi, sem dúvida, o que garantiu o sucesso dos movimentos sociais em torno dos direitos das minorias, de um manejo sustentável da terra, do bem-estar da infância e dos idosos, entre tantos outros temas (p. 3).

Para Ismar de Oliveira Soares (2004), pensar em ações que envolvam a comunicação e a educação se tornam palpáveis a partir do momento em que é possível perceber o quanto as configurações mais recentes das "novas práticas comunicativas evidenciam um uso cada vez maior das tecnologias de comunicação (rádio, televisão, Internet etc.) pelas organizações comunitárias" (p. 4). Assim, a partir de iniciativas de educomunicação, torna-se possível transmitir mensagens através da mídia - ainda que num âmbito local e de maneira independente - ampliando o debate a novos emissores, e, consequentemente, a uma real democratização da comunicação. A construção do que o autor chama de "sociedade da comunicação" seria pautada, então, por uma formação que estimula outras interpretações de mundo. Mas, de que maneira a comunicação chega até as crianças? E, no foco deste trabalho, como ainda muito pequena a criança cria uma relação com a imagem audiovisual que a cerca?

Segundo uma pesquisa realizada pelo Grupo de Pesquisa Educação e Mídia (Grupem) da Pontifícia Universidade Católica (PUC-Rio), em 2004, o Brasil já era considerado uma das sociedades mais audiovisuais do planeta. Em relação à televisão, são as crianças que compõem o maior segmento de espectadores da TV aberta, levando em consideração, inclusive, as programações que não são adequadas à faixa etária infantil. Deste modo

é lícito supor, portanto, que essa forte presença da televisão no cotidiano das crianças faz dela um importante agente de socialização que, ao lado da família, da escola e de outras instituições, ajuda a construir valores, identidades e imaginários (MIGLIORA; NÉRI; SANTOS In: DUARTE, 2008, p. 2).

A mesma pesquisa mostrou que, em geral, "a percepção que elas têm do mundo, através do que é veiculado pelos telejornais, é quase sempre de um lugar onde é impossível viver” (p. 162) em função das constantes informações relacionadas à violência que são veiculadas nos grandes veículos de comunicação - comumente usando de cenário para essas notícias as favelas - e que entram pela TV dentro da casa de milhões de famílias brasileiras, 
de diferentes contextos sociais. Martin-Barbero e Rey (2001) afirmam que "a mídia de massa televisiva indica a direção da crise da representação e as transformações que está atravessando a identidade da mídia" (p. 17).

Segundo Barbero (2003), da convivência extensa de crianças com a mídia surge uma empatia tecnológica, que, associada à empatia cognitiva, culmina em "novos modos de narrar e de perceber as identidades" (p. 66). Neste sentido, se faz necessário pensar em um meio que contemple a maior possibilidade de interação entre jornalista e público, a fim de influenciar para um incentivo a uma comunicação propícia ao senso crítico e a alteridade. A partir de agora este trabalho irá focar seus estudos em um dos meios mais interativos do jornalismo, o webdocumentário.

\section{Webdocumentário, uma nova possibilidade discursiva na educomunicação}

O webdocumentário é um formato midiático voltado exclusivamente para internet. Embora carregue em seu nome o estigma de um documentário para internet, este tipo de formato vai além. Trata-se do uso de diferentes modelos comunicacionais que são reunidos em um único site, dentre eles os que comumente têm mais destaque discursivo são os produtos audiovisuais.

O webdocumentário representa uma ruptura nas formas tradicionais de produzir um material audiovisual, pois sua estrutura é baseada em uma montagem interativa e não linear, diferente de outros modelos midiáticos. Para Cárlida Emerin e Beatriz Cavenaghi (2012), isso ocorre porque "a internet quebra a linearidade até então proposta pelo cinema e pela televisão e apresenta uma nova maneira de acesso ao conteúdo audiovisual” (p. 5). O que Beatriz Ribas (2003) chama de montagem de micronarrativas, onde mídias variadas - foto, texto, etc "fazem parte de diversas micronarrativas conectadas por links, permitindo ao receptor fazer escolhas, optar por diferentes caminhos, dando liberdade para a compreensão" (p. 5)

Gregolin, Sacrini e Tomba (2002) enxergam no webdocumentário a "viabilidade de uso do produto imagético na educação, suas formas de aplicação e manuseio ideológicos por se tratar de um pretenso recorte inquestionável da "realidade"' (p. 19). Ao criar um recorte inquestionável da realidade, criam-se a possibilidade de uma maior condição na visão do indivíduo sobre o eu e sobre o outro, mas agora no sentido da comunicação, o que culmina em um leque maior nas representações sociais e em novas formas de desmistificá-las.

Conclui-se que o webdocumentário é um forte aliado a processos pedagógicos, o que segundo Gregolin, Sacrini e Tomba (2002) estimula que a criança “deixe de ser visto como mero receptor de informações" (p. 46). É como se o ciberespaço recuperasse a possibilidade 
de comunicação para aqueles que vivem sob uma lacuna de representação existente nos outros veículos midiáticos. Dando voz a segmentos da sociedade que são pouco - ou nada representados nesses espaços. Conforme afirma Jorge Alberto S. Machado (2007)

\footnotetext{
Principalmente pelo fato de que nela qualquer cidadão pode assumir, ao mesmo tempo, uma variedade enorme de papéis - como cidadão, militante, editor, distribuidor, consumidor, etc. - superando as barreiras geográficas e, até certo ponto, as limitações econômicas (p. 269).
}

Deste modo, os atores sociais criam organismos de defesa e de representações sociais cruciais para uma nova construção do eu e do outro perante a sociedade. Com base nisso é possível afirmar que a opção deste ser um trabalho em webdocumentário fomenta essa possibilidade nas Moradias Zimbros, pois, como já foi elucidado, trata-se de um meio comunicativo, plural, com dimensões de autonomia, cooperação, interatividade, e, consequentemente, um forte potencial na construção da representação social, construção identitária, criatividade, senso crítico, e conhecimento humano.

\section{Janela Periférica: do processo ao resultado}

A experiência do Janela Periférica tentou agregar todas as discussões apresentadas até agora. Ou seja, repensar o olhar para a infância, o olhar para a favela a partir da educomunicação e utilizando o webdocumentário como ferramenta. $\mathrm{O}$ trabalho foi feito a partir de diversas oficinas realizadas com 27 crianças da Associação de Moradores das Moradias Zimbros (ASMOZI). As oficinas aconteceram semanalmente, de maio a setembro de 2013, totalizando 40 horas/aula. O pano de fundo motivacional para a realização destas oficinas era contribuir para a transformação social de crianças a partir do contato com a comunicação, que neste prisma pode servir de ferramenta na sua formação como indivíduo, estimulando a alteridade, transformação social, curiosidade, crítica, inventividade e formação do olhar.

Todo o conteúdo de produção - como direção, produção, roteiro, cinegrafia, som, argumentos e reportagens - foi idealizado e operacionalizado pelas próprias crianças. O envolvimento dos pesquisadores nesse processo da produção foi puramente na orientação e coordenação das ações que resultam neste webdocumentário, além de ministrar as oficinas de educomunicação. O resultado deste trabalho pode ser acessado no webdocumentário http://janelaperiferica.com.br/.

Dentre os temas abordados nas oficinas, estão: história da comunicação, teorias do cinema documental, tipos de enquadramentos e planos no telejornalismo e no cinema, tipos de 
profissionais do audiovisual (câmera, direção, produção, etc.), fotografia, roteiro, técnicas de animação em stop motion, noções sobre produção de conteúdos audiovisuais e montagem.

O primeiro mês da oficina serviu para apresentar o projeto às crianças, o que é comunicação, como manipular os equipamentos e como reconhecer o outro através da câmera. Observou-se neste período que para uma melhor metodologia seria necessário pensar uma demanda maior de oficinas práticas do que teóricas, tendo em vista que as crianças participam do projeto no contra turno escolar e se sentem impacientes com uma carga excessiva de conteúdos teóricos em sala de aula. A teoria passou a ser incorporada a prática, com exercícios específicos.

Neste período ainda houve resistência por parte de algumas crianças em ver o projeto como algo útil e entendível, levando em consideração que muitos deles não enxergavam viabilidade e lógica nesta produção. Frases como "Por que filmar esse lugar?" "É só morrer alguém na rua da minha casa que a TV vem filmar", "Nunca vi meu bairro bonito no jornal, é só lixo, morte e pessoas ruins", mostravam a visão das crianças sobre essa iniciativa, assim como uma certa resistência a ela.

No segundo mês, após a ambientação da pesquisadora, da proposta de trabalho, dos equipamentos e técnicas, em oficina as crianças definiram quais seriam os primeiros temas abordados no webdocumentário e o que seria necessário para realizá-lo. Os temas definidos foram futebol e um passeio documentado pelo bairro.

O principal resultado desta fase foi o evidente envolvimento das crianças com o projeto. Quebrou-se a barreira inibidora entre a criança e a câmera. Embora ela seja um elemento de estranhamento, nesta fase as crianças já se adaptaram e passaram a criar por meio dela várias imagens, com olhares criativos e autorais.

Depois da fase inicial de aproximação e definição de temas iniciou-se as produções e as aulas práticas se tornaram rotina. Mais que conhecimento técnico, esse processo serviu para que a criança percebesse o outro através da câmera, emergindo neste processo questões sociais sobre suas próprias vidas. Ou seja, a prática do que está sendo abordado na teoria.

No terceiro mês todos os temas foram definidos e a rotina de produção se fez frequente. Os projetos realizados até essa fase foram: um vídeo sobre um campeonato de futebol no bairro, e um vídeo sobre a festa julina que aconteceu na associação de moradores e um vídeo sobre um passeio pelo bairro, apontando coisas boas e ruins (que por fim foi dividido em dois materiais separados na finalização).

E o quarto mês serviu para finalizar a escolha completa dos temas a serem abordados assim como a produção de cada um deles. Neste mês, foi finalizado um vídeo das casas das 
crianças falando sobre suas famílias e outro da cantiga "Se essa rua fosse minha", interpretada por um dos participantes desta iniciativa.

O quinto e último mês serviu para finalizar detalhes que ficaram pendentes durante o processo de produção. Também neste mês as crianças aprenderam um pouco mais sobre como funciona a finalização/edição de um produto audiovisual. Ainda neste período ocorreu a estreia oficial dos filmes produzidos pelas crianças para a comunidade. Com um público de aproximadamente 100 pessoas, o evento serviu como uma espécie de encerramento oficial das atividades do projeto na comunidade.

O webdocumentário foi dividido em temas. Durante as oficinas do projeto Janela Periférica foram realizados um total de seis vídeos temáticos, além de fotos e outros materiais utilizados no webdocumentário. Vale ressaltar que todas as ideias, imagens e entrevistas foram pensadas, produzidas e realizadas pelas mãos e olhos das crianças participantes do projeto. Um elemento interessante de ser observado é a forte ligação das crianças que participam do projeto Janela Periférica com a rua. Esse elemento pode ser observado em todas as produções do projeto. Os filmes realizados nas oficinas foram:

- Arraiá - Um filme sobre a festa Julina do bairro. O vídeo tem 8’07”, nele as crianças optaram por fazer uma cobertura não roteirizada, baseando-se em técnicas do telejornalismo padrão, com passagem, e repórteres entrevistando participantes da festa.

- Bola na rede - Com 08'29”, o vídeo retrata um campeonato de futebol que acontece na Cidade Industrial de Curitiba, chamado "Campeonato dos Peladeiros". Para esta produção, optou-se manter uma linha muito próxima as típicas coberturas do telejornalismo diário, com um padrão de repórteres fazendo passagens e entrevistas.

- Minha casa, minha janela - Este filme, de 14’24, retrata temas como casa, família, cotidiano e as relações sociais entre as crianças e o bairro. Cada criança filmou a fachada da sua própria casa, com plano detalhe de aspectos definidos a seu modo durante a produção. Além disso foi gravada uma entrevista com cada uma das crianças, em que elas falam sobre como é morar naquela casa. Um filme baseado em técnicas do documentário.

- O Campinho - Este vídeo tem 7’25” e mostra um passeio pelo bairro com destino ao campinho de futebol. Trata-se de outro projeto não roteirizado, que surgiu em uma aula prática com uma proposta completamente livre, "sair fillmando por aí". As crianças escolheram sair da Associação de Moradores das Moradias Zimbros e ir caminhando até o campinho onde elas costumam treinar futebol e brincar. Durante o caminho as crianças falam sobre suas vidas, seu bairro, os problemas que acontecem nele e seus sonhos. O vídeo traz 
elementos do telejornalismo mesclados com o documentário, e vai sendo apresentado conforme as crianças vão se aproximando de seus destino: o campinho.

- Rua dos Brincantes - Um filme de 7'29” que traz reflexões das crianças sobre como é ser criança na periferia, das brincadeiras na rua, da liberdade, dos sonhos, das vantagens e desvantagens. A ideia inicial era falar sobre as diferenças entre as crianças que moram no centro da cidade, das crianças que moram em regiões de periferia Parte deste vídeo é a continuação da mesma diária de gravação do vídeo "O Campinho", mas agora com outro foco, discurso e imagens de cobertura captadas em outras diárias de produção.

- Se essa rua fosse minha... - Matheus Caik sonha em ser cantor, em uma das diárias de gravação, despretensiosamente, as crianças decidiram filmar o amigo. $\mathrm{O}$ resultado originou em um filme de 1'38', trata-se de um trabalho baseado na linguagem do videoclipe, o garoto caminha por uma das ruas principais do bairro enquanto canta a cantiga de roda "se essa rua fosse minha". O vídeo é apresentado no webdocumentário Janela Periférica na integra de como foi filmado, sem qualquer corte ou interferência gráfica durante a finalização.

\section{Considerações finais}

Tendo como foco a educomunicação no processo de produção, e o webdocumentário no processo de finalização e distribuição, é possível apontar que ambas formas de comunicação tiveram uma importante ligação neste projeto. As importantes referências no ato de pensar e realizar educomunicação, aliadas às múltiplas possibilidades midiáticas do webdocumentário, culminaram em um projeto que mostra diferentes pontos de vista, por diferentes mídias, sobre um mesmo bairro curitibano.

Para despertar o interesse das crianças e consequentemente incentivar o exercício do olhar e da crítica em cada uma delas foi necessário entender quem eram essas crianças, e de que maneira a periferia representa seu contexto social, além de onde a mesma periferia está posta na cidade de Curitiba. Neste prisma a pesquisa teórica foi de suma importância para compreender quais são os signos que ilustram a visão de mundo dessas crianças, e a partir deles encontrar maneiras viáveis de incentivar outras visões e possibilidades que vão além do senso comum.

A opção de utilizar a educomunicação como ferramenta para este processo foi de suma importância no resultado final do produto. Com isso, é possível completar que as discussões teóricas sobre os temas que abarcam este trabalho alicerçaram por completo o resultado final do projeto Janela Periférica. 
Pensando além do resultado exposto no webdocumentário é importante frisar que um dos elementos que legitima este projeto como uma real experiência de educomunicação é poder pensá-lo como um projeto de processos e não puramente resultados. Esperava-se que as oficinas de educomunicação originassem por fim um webdocumentário, sim. Porém, mais do que isso, esta iniciativa buscava a essência da educomunicação, pois se tratava de um projeto focado na importância do processo que se percorre até chegar ao produto final, e todas as descobertas que esse processo proporciona.

Ao participar da oficina de educomunicação do Janela Periférica, as crianças tiveram acesso a técnicas, equipamentos, formas e linguagens que possibilitam a comunicação social, mas não somente isso. Elas tiveram também a possibilidade de se expressar a partir dessas ferramentas comunicacionais, e ao se envolverem com tarefas da produção de conteúdos audiovisuais que resultariam no webdocumentário puderam emergir em diversas questões pessoais, com temas relacionados ao lugar onde vivem, e, consequentemente, com as suas próprias vidas.

Paralelamente às atividades de aprender a operar uma câmera ou se posicionar frente a ela, a ideia primordial era fazer com que as crianças percebessem o lugar onde moram, as pessoas que as cercam, as questões sociais presentes nestes espaços e a si mesmas. $\mathrm{O}$ exercício de se enxergar possibilitou o senso crítico sobre o seu bairro, este senso crítico proporcionou, agora, uma nova projeção sobre seu espaço. Desta vez interpretada e apresentada nos olhos e vozes das próprias crianças. São eles por eles mesmos, o discurso fica em primeira pessoa e a partir dele é possível entender questões antes não discutidas e analisadas por eles mesmos.

Deste modo é possível concluir que o projeto Janela Periférica foi importante para as crianças das Moradias Zimbros, e para os demais moradores da região, pois foi em sua essência um espelho da realidade social destas vidas e seus cotidianos.

Durante o processo das oficinas nos deparamos com um cenário onde a maioria das crianças encarava a representação da imprensa e da comunicação na periferia ligadas intrinsecamente a tragédia, levantando indagações sobre a imprensa que só registra nas ruas do bairro notícias que envolvem aspectos violentos e negativos. Deste modo é possível prever que na maioria das vezes seria este o retrato que essas crianças teriam de seu bairro. Este projeto aponta para outras possibilidades, com ele as crianças podem enxergar e transmitir um olhar diferente sobre a mídia e sobre o ato de noticias questões relacionadas a periferia, sejam elas boas ou ruins, mas acima de tudo, reais. 
DITO EFEITO - ISSN 1984-2376 ANO IV, Vol. 4, N. 5, Jul.-Dez. 2013 UTFPR-CAMPUS CURITIBA

Este processo reflexivo é fundamental na formação da criança, sendo de suma importância sua percepção ainda na infância. É fundamental para sua formação que a criança pratique esse olhar aguçado sobre a periferia e sobre as questões sociais que ali se relacionam diretamente com suas vidas. Conclui-se que por meio disto este processo cria uma rede de inclusão social a partir da comunicação e pode servir como uma ferramenta de visibilidade, reconhecimento identitário e transformação social da comunidade das Moradias Zimbros. (Recebido em 05/12/2013, aprovado em 11/12/2013)

\section{Referências}

ASMOZI, 2013. Site da associação de moradores das moradias zimbros. Disponível em http://www.asmozi.org.br/ . Acessado em 16/01/2013

BURGOS, Marcelo Baumann. Favela e luta pela cidade: esboço de um argumento. In: SILVA, Jailson de Sousa. O que é favela, afinal? Rio de Janeiro: Observatório de Favelas, 2009.

DEMARTINI, Zeila de Brito Fabri. Diferentes infâncias, diferentes questões para a pesquisa. In: MARTINS FILHO, A. J. ; PRADO, P. D. (Org.) Das pesquisas com crianças à complexidade da infância. Campinas/ SP: Autores Associados, 2011.

EMERIM, Cárlida ; CAVENAGHI, Beatriz. Contribuições da linguagem dos webdocumentários para o webjornalismo audiovisual. In: XIII Congresso de Ciências da Comunicação na Região Sul, 2012, Chapecó (SC). Intercom. Chapecó (SC): UNOCHAPECÓ e INTERCOM, 2012. v. 1. Disponível em

http://www.intercom.org.br/papers/regionais/sul2012/resumos/R30-1661-1.pdf . Acessado em $25 / 05 / 2013$

GREGOLIN, Maíra; SACRINI, Marcelo; TOMBA, Rodrigo A. Webdocumentário - Uma ferramenta pedagógica para o mundo contemporâneo. BOCC. Biblioteca On-line de Ciências da Comunicação, v. 4, p. 1, 2004. Disponível em http://www.bocc.ubi.pt/pag/tomba-rodrigoweb-documentario.pdf. Acessado em 20/05/2013.

KRAMER, Sonia. Linguagem, cultura e alteridade. Para ser possível uma educação depois de Auschwitz, é preciso educar contra a barbárie. Enrahonar, Barcelona, v. 31, p. 149-159, 2000.

LAJOLO, Marisa. Infância de papel e tinta. In: FREITAS, Marcos César. História social da infância no Brasil. São Paulo: Cortez/ USF; IFAN, 1997.

MACHADO, Jorge Alberto S. Ativismo em rede e conexões identitárias: novas perspectivas para os movimentos sociais. Sociologias, 2007, vol., no.18, p.248-285. ISSN 1517-4522. 
DITO EFEITO - ISSN 1984-2376 ANO IV, Vol. 4, N.o 5, Jul.-Dez. 2013 UTFPR-CAMPUS CURITIBA

MARTIN-BARBERO, Jesus; REY, German. Os exercícios do ver: hegemonia audiovisual e ficção televisiva. São Paulo: Editora SENAC, 2001.

MARTIN-BARBERO, José. Globalização comunicacional e transformação cultural, 60-78. In: Morais, Denis de (org.). Por uma outra comunicação: mídia, mundialização cultural e poder. Rio de Janeiro: Record, 2003.

MIGLIORA, Rita; NÉRI, Gleilcelene Gomes; SANTOS, Fernando Rodrigo dos.

O que as crianças pesnam sobre os telejornais. In: DUARTE, Rosália (Org.). A televisão pelo olhar das crianças. São Paulo: Cortez, 2008.

PRADO, Patrícia Dias. "Agora ele é meu amigo": Pesquisa com crianças, relações de idade, educação e culturas infantis. In: MARTINS FILHO, A. J. ; PRADO, P. D. (Org.) Das pesquisas com crianças à complexidade da infância. Campinas/ SP: Autores Associados, 2011.

RIBAS, Beatriz. Contribuições para uma definição do conceito de Web Documentário. In: MACHADO, Elias; PALACIOS, Marcos. Modelos de Jornalismo Digital. Salvador:

Calandra, 2003

SCHAUN, Angela. Educomunicação: Reflexos e princípios. Rio de Janeiro: Mauad, 2002.

SCLIAR, Moacyr. Um país chamado infância. São Paulo: Ática, 1995.

SOARES, Ismar de Oliveira. Alfabetização e Educomunicação: O papel dos meios de comunicação e informação na educação de jovens e adultos ao longo da vida. 2004.

Disponível em

http://www.direitoacomunicacao.org.br/index2.php?option=com_docman\&task=doc_view\&g $\mathrm{id}=138 \&$ Itemid=99999999. Acesso em 03/04/2013.

STROZEMBERG, Pedro. Alguém tem receio de ser multado na favela?. In: SILVA, Jailson de Sousa. O que é favela, afinal? Rio de Janeiro: Observatório de favelas, 2009.

VALLADARES, Licia do Prado. A invenção da favela- Do mito de origem a favela.com. Rio de Janeiro: Fundação Getúlio Vargas, 2005. 
DITO EFEITO - ISSN 1984-2376 ANO IV, Vol. 4, N. 5, Jul.-Dez. 2013 UTFPR-CAMPUS CURITIBA 